\title{
Self-reported history and saliva analyses of recreational drug use among students in a public university in Mombasa, Kenya
}

\section{Valentine Budambula ( $\sim$ valbudambula@gmail.com )}

Technical University of Mombasa Faculty of Applied and Health Sciences https://orcid.org/0000-00032852-3973

\section{Joan Jelagat}

Technical University of Mombasa

Nancy L.M. Budambula

University of Embu

Moses M Ngari

KEMRI Wellcome Trust Research Programme

Research article

Keywords: Self reported drug use, saliva analysis, poly-drug use, and university students

Posted Date: May 9th, 2020

DOl: https://doi.org/10.21203/rs.3.rs-25442/v1

License: (9) This work is licensed under a Creative Commons Attribution 4.0 International License.

Read Full License 
Self-reported history and saliva analyses of recreational drug use among students in a public university in Mombasa, Kenya

Jelagat Joan, Bsc ${ }^{1}$; Budambula Valentine, $\mathrm{PhD}^{1}$; Budambula L.M. Nancy, $\mathrm{PhD}^{2}$; and Ngari Moses, DPhil ${ }^{3}$

${ }^{1}$ Department of Environment and Health Sciences, Technical University of Mombasa, Kenya

${ }^{2}$ Department of Biological Sciences, University of Embu, Kenya

${ }^{3}$ KEMRI-Wellcome Trust Research Programme, Kilifi, Kenya 


\section{AUTHOR CONTACTS}

Valentine Budambula, $\mathrm{PhD}$

Department of Environment and Health Sciences

Technical University of Mombasa

P. O. Box 90420-80100, Mombasa, Kenya

Phone: +254-722-822-448

Email: valbudambula@gmail.com

Jelagat Joan, Bsc

Department of Environment and Health Sciences

Technical University of Mombasa

P. O. Box 90420-80100, Mombasa, Kenya

Phone: +254-726-238-241

Email: joanchelajc@gmail.com

Budambula L.M. Nancy, PhD

Department of Biological Sciences,

University of Embu, Kenya

P. O. Box 6 - 60100. Embu, Kenya

Phone: +254-722-524-041

Email: nancy@embuni.ac.ke and nbudambula@yahoo.com

Moses M. Ngari, DrPhil

KEMRI Wellcome Trust Research Programme,

P.O Box 230-80108, Kilifi, Kenya

Phone +254-720-865-164

Email: mngari@kemri-wellcome.org

\section{Please address any correspondence to:}

Valentine Budambula, PhD

Email: valbudambula@gmail.com 


\begin{abstract}
Background: Recreational drug use among students in tertiary institutions remains a public health concern. Despite documentation of drug use in Kenyan universities, most of the studies are based on self reported history which is prone to social desirability bias. It is in this context that we sought to establish actual drug use among university students.
\end{abstract}

Methods: We investigated self reported and confirmed drug use. Using proportionate to size and snowball sampling methods 380 respondents were enrolled. Social demographic characteristics and self reported drug use history were documented using a participant assisted questionnaire. Actual drug use was determined qualitatively using 6 panel plus alcohol SalivaConfirm ${ }^{\mathrm{TM}}$ Saliva Test kit.

Results: Most (75\%) of the participants were sexually active. Based on self reported history, 221 $(58 \%)$ students reported a life time ever use of drugs while based on saliva testing (193) 51\%) tested positive for at least one drug. Alcohol, tobacco products (cotinine), marijuana and amphetamine or khat were the most preferred drugs. The usage was either solely, concurrently or simultaneously. In the multivariate regression model, compared to students with no sexual partner having multiple sexual partners was associated with risk of testing positive for any drug: adjusted risk ratio (aRR) of 2.06 (95\% CI 1.26, 3.37). Compared to residence within the university hostel and its environs, residing in town was associated with risk of testing positive for any drug: aRR 1.67 (95\%CI 1.16, 2.42). Having one and multiple sexual partners were associated with risk of self-reported drug use: aRR of 1.55 (95\% CI 1.05, 2.28) and 2.05 (95\% CI $1.28,3.27)$ respectively. While compared to residence in university hostel and its environs, residing in town was associated with risk of self-reported drug use: aRR 1.48 (95\% CI 1.05, 2.08).

Conclusion: Drug use is indeed a problem among university students with a significant number engaging in poly-drug use. Alcohol, tobacco products (cotinine), marijuana and amphetamine or khat were the most preferred drugs. Future interventions should focus on continuing students, students' residence and those who are sexually active.

Key words: Self reported drug use; saliva analysis; poly-drug use; and university students 


\section{Background}

Substance use, abuse and addiction remain a major global public health problem. It is estimated that in 2017, about 271 million people worldwide aged 15-64 years used drugs at least once. Approximately 35 million of people who used drugs (PWUDs) suffered from drug use disorders (Error! Reference source not found.). Cannabis sp is the most widely used illicit drug in the African region. The highest prevalence and incidence rates of Cannabis sp was $5.2 \%$ and $13.5 \%$ respectively in West and Central Africa (Error! Reference source not found.).

University students have a heightened risk for substance use as this is the time young people transition to adulthood. Many university students live independently and make behavioural health decisions without direct parental or adult oversight. In addition, most university students tend to share living quarters with strangers and may be exposed to normative values or culture that differ from parental values. Moreover, living off-campus independently or with peers has been associated with riskier drinking than living on-campus $(3,4,5,6)$.

Throughout the United States of America (USA) in 49 medical colleges, $91.3 \%$ and 26.2\% of medical students reported to have used alcohol and marijuana respectively in the past year. Among those who consumed alcohol, 33.8\% had consumed five or more drinks in one sitting in the past two weeks (7). In mid-Atlantic USA, marijuana was the most reported commonly used drug among college students with the highest annual peak occurring in year three of study (8).

Among Norwegian students, a study on Alcohol Use Disorder Identification Test (AUDIT) reported that approximately 53.0\% of the students had an AUDIT score of eight or above. This level is categorized as hazardous drinking (Erevik et al., 2017). Some of the risk factors for drug use among Norwegian students included: being a single male without children; a native Norwegian; being non-religious; extroverted and having failed in examinations more than once $(9,10)$.

Preferred drugs among university students in India were alcohol, smoked and non smoked tobacco as well as cannabis (Arora et al., 2016). Most students used these drugs to relieve psychological stress, to celebrate special occasions and to reduce fatigue. In addition, drug use in this group has been linked to curiosity and familial use $(11,12)$. In Kuwait, drug use was 
positively associated with age, poor academic performance, high family income, being an only child, having divorced parents and graduation from a private high school (13).

In Sudan being male was predictive of drug use. Tobacco, cannabis and alcohol were the most consumed drugs in Sudan (14). A meta-analysis of 24 studies in Ethiopia showed that khat chewing was rampant among university students. Being male, having a family that practiced khat chewing and a friend's khat chewing habits were predictive of drug use (15). In Kenya, drug use among university students is highly prevalent. For example, in Eldoret, a lifetime prevalence rate of alcohol and tobacco use is approximately $51.9 \%$ and $42.8 \%$ respectively (16).

Despite extensive documentation of drug abuse among university students, most of the studies are based on self reported history which is prone to social desirability bias. It is for this reason that this study sought to determine drug use patterns based on self reported history, actual drug use and social-demographic features associated with drug use among university students.

\section{Materials and Methods}

The study was conducted at a public university located in the coastal town of Mombasa in Kenya in 2017. This was a cross sectional study. Purposive, convenience and snowball sampling methods were used to enroll participants. Social demographic characteristics and self reported drug use history were documented using a participant assisted questionnaire. Drug use was confirmed using 6 panel plus alcohol SalivaConfirm ${ }^{\mathrm{TM}}$ Saliva Test kit as per manufacturer's instructions. These kits utilize monoclonal antibodies to detect high levels of illicit drugs in human oral fluids. We assessed use of cocaine, opiates, tetrahydrocannabinol, amphetamine, benzodiazepines, cotinine and alcohol.

\section{Statistical methods}

All categorical variables were reported as proportions with their respective percentages while age was summarized using mean and standard deviation. To examine the demographic features associated with confirmed positive test results for any drug, we used log-binomial regression analysis and reported transformed regression coefficient into risk ratios (RR) and their respective 95\% confidence intervals. The dependent variable was the binary drug test results from saliva 
analysis (either positive or negative). In the univariate models, we tested each demographic variable separately. In the multivariate regression analysis, all the demographic variables tested in the univariate models were included to minimize risk of variable selection bias. Log-binomial regression analysis was preferred because the logistic regression overestimates measure of effects for common outcome with a prevalence of more than $10 \%$ (17). As a sensitivity analysis, we also performed regression analysis of demographic factors associated with self reported drug use to assess if they would be similar to those of saliva test confirmed drug use. We assessed the multivariate regression model performance using area under receiver operating characteristics curve (AUC).

Statistical significance was assumed at $\alpha<0.05$. All statistical analyses were performed using STATA version 15.1 (StataCorp, College Station, TX, USA).With a conservative proportion of university students using drugs of 50\% (in absence a relevant prevalence in our settings) and level of significance of $5 \%$ we required a sample of 384 students. We utilized sample size formulae as previously used by Fischer et al (18). Out of the 384 participants, four declined to consent to saliva testing and were therefore not included in the final analysis.

\section{Results}

\section{Socio-demographic characteristics of participants}

From February 2017 to March 2017, we recruited 380 participants whose mean (SD) age was

21.9 (2.1) years and $118(31 \%)$ were female. Majority (86\%) of the study participants were enrolled in undergraduate degree programmes. Study participants were distributed as follows; $18 \%, 19 \%, 29 \%$ and 33\% in first, second, third and fourth year of study respectively. In this 
study, participants who were first born by birth order were28\% and 116 (31\%) of participants were from the School of Business. In addition, 95\%reported never having been married and $45 \%$ received a pocket money <USD 50 per month. One hundred and eight (28\%) reported having pocket money that was above USD 50 but below USD 100 per month. Two hundred and sixty two (61\%) and $52(14 \%)$ had one and multiple sexual partners respectively. Two hundred (72\%) had used a condom during their last sexual intercourse as shown in Table 1.

\section{Drug use patterns based on self reported history}

Of the 380 students, $221(58 \%)$ reported to have ever used drugs in a lifetime. One hundred and thirty eight (36\%) participants reported alcohol use, 103(27\%) had used marijuana, 92(24\%) had ever consumed shisha, 76(20\%) had ever smoked cigarette and 68 (18\%) had ever chewed khat. Poly-drug use among these participants was best described using a 5-class solution as used by Quek and colleagues (19). The following drug combinations were the most popular: alcoholmarijuana-shisha-cigarette-khat; alcohol-marijuana-shisha-cigarette; alcohol-marijuana-shisha; alcohol-marijuana and lastly alcohol-marijuana-shisha-cigarette-khat-diazepam. These findings have been summarized in Table 2 and Figure1Arespectively.

\section{Confirmed drug use patterns based on saliva tests}

Qualitative saliva analysis indicated that, $193(51 \%)$ were positive for at least one drug. The results were as follows: alcohol (32\%); cotinine (30\%), tetrahydrocannabinol (25\%); amphetamine (16\%); benzodiazepines $(2.7 \%)$ and Opiates (1.3\%). Out of the 193 participants who tested positive: $35.2 \%$ were mono-drug users; $31.6 \%$ were positive for two drugs; $22.3 \%$ used three drugs; $9.8 \%$ four drugs and one percent $(1 \%)$ were positive for five drugs. The common drug combinations were as follows: alcohol- amphetamine- benzodiazepines- THCcotinine; alcohol-amphetamine-benzodiazepines-THC; alcohol-amphetamine-benzodiazepines; 
alcohol-amphetamine; and alcohol-amphetamine-THC-cotinine-opiates (Table 2 and Figure 1B).

\section{Socio-demographic factors predicting drug use.}

Based on confirmed drug; univariate regression analysis predicted that birth order, year of study, students' residence and number of sexual partners were associated with risk of testing positive for any drug. Being a third born predicted drug use with a crude risk ratio (CRR) of 1.36 (95\% CI 1.03, 1.79). In comparison to participants in year one of study, participants in year two, three and four of study were associated with higher risk of testing positive for any drug with CRR of 1.60 (95\% CI 1.08, 2.37), 1.76 (95\% CI 1.22, 2.54) and 1.49 (95\% CI 1.02, 2.17) respectively. Compared to residence in the university hostel and its environs, residence within town was associated with risk of testing positive for any drug: CRR 1.94 (95\% CI 1.37, 2.73). Compared to students with no sexual partner, having one or multiple sexual partners was associated with adjusted risk ratio of $1.67(95 \%$ CI 1.12, 2.49) and 2.58 (95\% CI 1.62, 4.13) respectively. In the multivariate regression model, the effect of birth order and year of study attenuated. However, having multiple sexual partners was associated with the risk of testing positive for any drug adjusted risk ratio of $2.03(95 \%$ CI 1.24, 3.33). Compared to residence in university hostel and its environs, residence within town was associated with risk of testing positive for any drug: aRR 1.67 (95\% CI 1.16, 2.42). The multivariate regression model area under receiver operating characteristic curves (AUC) was 0.77 (95\% CI 0.72, 0.82) as summarized in Table 3.

Based on self reported history, univariate regression analysis indicated that the year of study, amount of pocket money, student residence and the number of sexual partners were associated with history of lifetime drug use. Compared to students in year one of study, students in year two, three and four of study were associated with higher risk of history of lifetime drug use; crude risk ratios 1.48 (95\% CI 1.05, 2.07), 1.58 (95\% CI 1.15, 2.16) and 1.45 (95\% CI 1.06, 2.00) respectively. Compared to residence in university hostel and the university environs, residence within Mombasa city was associated with risk of testing positive for any drug: CRR 1.70 (95\% CI 1.23, 2.34). Having pocket money between USD50 and USD 100 was associated with crude risk ratio of $1.42(95 \%$ CI 1.05, 1.91) compared to pocket money that was less than USD 50 per month. However, in the multivariate regression model, the effect of year of study 
and amount of pocket money attenuated. Compared to students with no sexual partner, having one or multiple sexual partners were associated with adjusted risk ratio of 1.54 (95\% CI 1.04, 2.27) and 2.03 (95\% CI $1.27,3.25)$ respectively. While compared to residence within the university hostel and its environs, residing in town was associated with risk of self-reported drug use: aRR $1.48(95 \%$ CI 1.05, 2.08). The multivariate regression model area under receiver operating characteristic curves (AUC) was 0.75 (95\%CI 0.71, 0.80) as summarized in Table 4.

\section{Discussion}

The overall prevalence of lifetime ever use and confirmed current use for at least one drug was58\% and $51 \%$ respectively. Predictors of drug use were being a third born child, year of study, receiving pocket money ranging between USD50 andUSD100 and being sexually active. This was applicable for both self reported history and confirmed drug use.

In this subpopulation, being a third or fourth born child increased the risk of drug use while being a second born was protective. These results corroborate findings of a study carried out in the Netherlands among adolescents whereby acute alcohol intoxication was more likely to occur in participants who had an older sibling. Thus being an only child or the firstborn child was considered a moderating factor for acute alcohol intoxication (20). Similarly, in Sweden after born siblings had a higher likelihood of getting hospitalized for both alcohol and narcotics use (21). This could be because the later born children are likely to be exposed to drugs at younger ages through older siblings or relatives. In most family set ups lastborns often have the position of the baby in the family. They are likely to be more pampered and spoilt through deprivation on independence (22). It is important to note that birth order does not necessarily imply causation of substance use but it could be part of a complex combination of etiopathogenic predictors.

Year of study predicted drug use as participants in second, third as well as fourth year and above had an elevated risk of substance consumption. Similar findings were reported in Ethiopia where being in the third year of study compared to first year increased the odds of substance use (23). In Sudan, being in third year carried a higher risk of drug use than in fifth year of study (14). Findings on association between third year of study and drug use are comparable to an eight year longitudinal analysis in Mid-Atlantic that reported highest annual peak of marijuana use in year three of study (8). This could be attributed to factors like academic-related stress (24), poor social skills thus increased vulnerability to peer pressure to use drugs (25), limited physical 
activities (26) and poor quality dating relationships (27). All the aforementioned factors combined increased vulnerability to stress and depression which in turn heightens drug use as a form of self medication. Moreover, based on general observations, most universities tend to pay more attention to students in their first year of training than students in subsequent years. This is evidenced by matriculation ceremony and life skill related courses that are mandatory in first year. Additionally, most parents tend to lose touch with their children as they progress to senior years because they perceive the later to have matured. Less parental closeness has been reported to be a predictor of substance use (28).

Living within the university hostels or around the university was a moderating factor in this study. On the other hand, students who lived away from the university around town were at the highest risk of drug use. Similar results were reported among university students in the Northeast of the United States where living off campus posed the highest risk of alcohol use (29). These findings are similar to the findings of a study carried out at the University of Nairobi in Kenya where students living off campus were more likely to use drugs as compared to their on-campus counterparts (30). This could be attributed to the fact that off-campus residences are often unregulated. The students living away from the University are more likely to be residing on the low-income side of town. Some of these residences are located next to entertainment venues and drug dens. Poor neighbourhoods act as a haven for drug peddlers and illicit liquor breweries making drugs easily accessible.

Higher risk of drug use was reported among students with pocket money ranging between USD50 and USD 100. Students with extremely low income ( $\leq$ USD 50) and very high income were less likely to use drugs. Extreme poverty and superfluity seem to be a moderating factor in this study. These findings differ from results of a study across 23 public and private USA institutions that reported undergraduates with high socio-economic status were more likely than peers to use marijuana as well as practice poly drug use (31). Similarly, among university students in Ethiopia, having a higher monthly income predicted drug use (32). Among high school students in North Carolina, having a weekly disposable income over USD 50 was a correlate of current hookah use (33). In Kuwait, students with high family income were more likely to use shisha (13). This could be attributed to the fact that drug use has a cost implication. The correlation between choice for drug and income needs to be treated cautiously. For example 
shisha and cocaine are considered as life style drugs and linked to the relatively affluent persons. On the other hand, alcohol, marijuana and cigarettes are linked to moderate or low income earners.

In the present study, students reporting drug use were likely to be sexually active. These findings correspond to the results of a study carried out at Mbarara University in Uganda where students who reported alcohol use were more likely to be sexually active. Additionally, 33\% of the sampled students engaged in multiple sexual partnerships (34). University students in nine countries belonging to the Association of Southeast Asian Nations (ASEAN) with two or more partners in the past 12 months were significantly more likely to be current tobacco smokers and binge drinkers (35). Elsewhere still, among university students amplified association between alcohol and risky sexual behaviors has been reported to be influenced by partner characteristics as well level of alcohol intoxication $(36,37)$. It is important to note that alcohol intoxication not only results into psychomotor impairment but it also affects cognitive processes such as perception and judgment thus contributing to high sexual partnerships. The positive association between higher use of marijuana, khat as well as tobacco products and multiple sexual partnerships is well documented $(38,39)$. This relationship could be linked to the fact that drugs like alcohol reduce inhibition towards sex. A drug like bhang which is a form of marijuana acts as a vasodilator thus enhancing sexual libido and performance.

Based on self reported history participations were likely to use alcohol, marijuana, shisha, cigarettes and khat. Confirmatory tests agreed with reported drug use as most participants tested positive for alcohol, cotinine, tetrahydrocannabinol and amphetamine. Cotinine is an alkaloid present in tobacco (Nicotiana tabacum) and a predominant metabolite of nicotine (39) while tetrahydrocannabinol (THC) is the active chemical in Cannabis sp (40).

The high prevalence of alcohol usage in the present study concurs with a report by National Authority for Campaign against Alcohol and Drug Abuse (NACADA) in Kenya. In this report, alcohol was the most abused drug by the youth aged 15-24 years (41). Similarly, consumption of alcohol by almost half of university students has been previously reported in Ethiopia (23) and Uganda (34). Use of alcohol among university students seems to be a major problem in the three Eastern Africa countries of Kenya, Ethiopia and Uganda. Outside Africa, the prevalence rate of 
alcohol consumption among University students ranged from $20 \%$ to $33 \%$ in Iran, Ireland and the United Kingdom $(42,42)$.

The rampant use of alcohol by university students can be attributed to the fact that alcohol is considered a gateway drug. The gateway drug hypothesis proposes that the pattern of legal substances use precedes the progressive use of illicit substances (44). Consequently, the gateway pattern of drug initiation follows a normative sequence commencing with alcohol and tobacco use during adolescence. This is followed by cannabis use with progression to other illicit drugs like cocaine and heroin in adulthood (44). Additionally, the college environment could also be playing a role in alcohol consumption. Some of the risky environmental factors include living in a hostel with a higher number of room-mates, having been in the University for a long spell, participation in student folklore, pre-partying and celebrations (46). The wide use of alcohol could be due to its legality in most countries whereby its usage is only regulated but not prohibited. For example in Kenya, alcohol usage is controlled under the alcoholic drinks control act (47). This legality makes alcohol easily available, accessible, acceptable and affordable.

In this study tobacco products were the second most popular drug used and students were likely to smoke cigarettes or shisha. This was supported by the participants testing positive for cotinine which is a nicotine metabolite. These findings parallel the findings of a study that sought to determine shisha use among students in a private university in Rwanda. This study reported a prevalence of $26.1 \%$ (48). In Kenya, a lifetime prevalence rate of tobacco use of $42.8 \%$ was previously reported by Atwoli et al (16) in Eldoret. Elsewhere in Sudan, tobacco use was most prevalent among universitystudentsat13.7\% (14). Smoked and non smoked tobacco was one of the most preferred drugs by university students in India (11).

High popularity of shisha use is partly because of societal fashion trends, peers' pressure and the presence of aromatic flavours like cappuccino chocolate, mint as well as coconut among others (49). Prior to the shisha ban in 2017 under the "Public Health Act" (50), shisha smoking was considered a pastime activity in Mombasa. The ban was partly influenced by the associated health risks. For example, an hour-long hookah smoking session involves 200 puffs, while smoking an average cigarette involves 20 puffs. Additionally, shisha tobacco and smoke contain several toxic agents known to cause lung, bladder as well as oral cancers (51). Use of other tobacco products is not illegal but is regulated under Tobacco Control Act, 2007 (52). Despite 
the stringent guidelines on tobacco use under this Act, the implementation process is weak and slow.

The present study reports habitual use of marijuana by university students. These findings concur with results in South Africa (SA) where 30.9\% of students reported that they had ever used Cannabis and $12 \%$ were current users (53). In mid-Atlantic USA marijuana was the most commonly used drug among college students in every year of study (8). Likewise, across 49 medical colleges in the USA about $26.2 \%$ of medical students had used marijuana in the past one year (7). The Narcotic Drugs and Psychotropic Substances Control Act (54) classify the possession, sale, growing and distribution of marijuana in Kenya as illegal. Despite this marijuana is unlawfully grown in inaccessible areas or hidden between other crops in Kenya making it relatively easily available and accessible. It can be peddled is small quantities in form of rolls for as low as USD 0.10 thus making it affordable. The cost implication contributes to the popularity of marijuana in this special sub-population. Other than the socio and legal consequences, the health effects should be of concern to the administration of learning institutions. Of great concern are the effects induced by delta-9-tetrahydrocannabinol (THC) on verbal, thinking and working memory (55).

Khat a substance that is structurally related to amphetamine was commonly consumed by students in the present study. Findings indicating high prevalence of khat use are similar to a systematic review that reported khat as one of the most consumed substances among university students in Ethiopia (56). Further, a meta-analysis indicated that the pooled prevalence of current khat use among university students was highest in Saudi Arabia (18.9\%) followed by Ethiopia 13.6\% and $13 \%$ in Yemen (57). Khat contains two major ingredients, namely cathine and cathinone which are structurally related to amphetamine. Testing positive for amphetamine could be due to khat chewing that is a common trend in Kenya and more so in Mombasa. Khat seems to be an emerging gateway drug.

In the present study, a significant proportion of university students who tested positive were poly-drug users. Irrespective of the method used to record data, alcohol, tobacco products, marijuana and amphetamine or khat were the most preferred combinations. Concurrent and simultaneous use of cannabis and tobacco has been previously reported amongst university 
students in Spain and Brazil $(58,59)$. In Ethiopia, khat use was strongly and positively associated with alcohol consumption (60).

Poly drug use could be for purposes of enhancing the potency of a drug, reducing its side effects or alleviating the withdrawal symptoms. For example drinking alcohol immediately after smoking Cannabis intensifies the effects of the later. This is so because alcohol increases the absorption of THC thus enhancing plasma THC levels (61). On the other hand, alcohol dependence and tobacco smoking have been shown to be highly co-morbid. Tobacco smoke is reported to slow down the adaptive recovery of gamma-aminobutyric acid $\left(\mathrm{GABA}_{\mathrm{A}}\right)$ receptors during extended alcohol abstinence. This may contribute to alcohol relapse and the perpetuation of smoking in users who attempt to abstain. Poly-drug use among university student can also be attributed to college environment. The college environment not only facilitates the acquisition of these substances but also contains environmental cues that trigger substance craving (62).

This being a cross-sectional it is difficult to determine whether the outcome followed exposure in time or exposure resulted from the outcome. Strength of the study is anchored on confirmed drug use. This study was able to detect drugs which are currently being consumed using saliva analysis. Although saliva analysis is not prone to social desirability bias it, only detects drugs used in the past few days. Blood and hair analyses can detect drugs used in a longer window period. To the best of our knowledge this is the first study in Kenya to document validated drug use among university students.

\section{Conclusion}

A lifetime ever use of drugs was $58 \%$ based on self reported history and $51 \%$ when determined by saliva tests. Being a latter born, in the third year of study with moderate income, residing outside the university hostel or its environs and having multiple sex partners were strong predictors for drug use. Irrespective of the method used to record data, alcohol, tobacco products, marijuana and amphetamine or khat were the most preferred drugs. The usage of these drugs was solely, concurrently or simultaneously.

An integrated approach for preventing substance use among this young population is warranted and crucial. Future interventions should focus on students who have been on campus for a longer duration and those who are sexually active. The policy makers and university management 
should prioritize expansion of on-campus accommodation. Findings of this study may be used as the baseline data for future studies. We recommend comparative studies be done using selfreported data saliva, blood and hair analyses.

\section{Declarations}

\section{Ethics approval and consent to participate}

The study was conducted in accordance with the Helsinki Declarations. The study was approved by Pwani University Ethical Review Committee (ERC/Msc/034/2016).Permission to carry out the study was granted by the University administration. Informed verbal consent was obtained from each participant. No name was recorded on the participant assisted questionnaire or used anywhere in the study.

\section{Consent for publication: Not applicable}

\section{Availability of data and materials}

The data sets analyzed during the current study are available from the corresponding author on reasonable request.

Competing interests: The authors declare that they have no competing interests.

Funding: We did not receive any funding towards this study.

\section{Authors' contribution}

JJ, VB, NLMB and MN designed the study and collected data. MN and VB performed statistical analyses. JJ and VB co-drafted the manuscript. NB and MN critically revised the manuscript. All authors have read and approved the final manuscript.

\section{Acknowledgements}

We thank the study participants and university management for their cooperation and support during the study. 
Table 1: Selected characteristics of students attending a public university in Mombasa, Kenya in 2017

Socio demographic characteristics

Age in months, mean \pm sd Total $(\mathbf{N}=\mathbf{3 8 0})$

Gender - N (\%)

Male

$21.9 \pm 2.1$

Female

$262(69)$

Education level - N (\%)

Degree student

$118(31)$

Diploma student

Birth order- N (\%)

First born

$2^{\text {nd }}$ born

$328(86)$

$3^{\text {rd }}$ born

$52(14)$

$4^{\text {th }}$ born and above

107 (28)

$77(20)$

$74(20)$

$122(32)$

School enrolled in - N (\%)

School of Business $116(31)$

School of Applied and Health Sciences 100 (26)

School of Engineering

$89(23)$

School of Humanities \& Social Sciences

$49(13)$

Institute of Computing and informatics

$26(6.8)$

Year of study

First Year

68 (18)

Second Year

$74(20)$

Third Year

111 (29)

Fourth Year and above

$127(33)$

Residence or accommodation type- N (\%)

University Hostel

$34(9.0)$

University environs

110 (29)

Mishomoroni and Kisauni

$84(22)$

Within town (Makupa, Sparki \& Majengo)

$116(31)$

Bamburi and Bombolulu

$36(9.5)$

Marital status- N (\%)

Never Married

$361(95)$

Married/cohabiting

$19(5.0)$

Income/Pocket money per month (USD)- N

$<50$

$170(45)$

Between 50 and 100

$108(28)$

$>100$

$102(27)$

\section{Current number of sexual partners- N (\%)}

None

$96(25)$

One

$232(61)$

Two and above

$52(14)$

Used condom during last sexual intercourse-

200 (72)

*Results are $\mathrm{N}(\%)$ unless specified 
Table 2: Self reported drug use and saliva drug tests in a sample of students in a public university in Mombasa, Kenya in 2017

\begin{tabular}{|l|c|}
\hline Reported drugs $-\mathbf{N}(\%)$ & $\mathrm{N}=221$ \\
\hline Alcohol & $138(62)$ \\
\hline Marijuana & $103(47)$ \\
\hline Shisha & $92(42)$ \\
\hline Cigarette & $76(34)$ \\
\hline Khat & $68(31)$ \\
\hline Diazepam & $7(3.2)$ \\
\hline Heroin & $6(2.7)$ \\
\hline Rohypnol & $6(2.7)$ \\
\hline Drugs tested positive- N (\%) & $\mathrm{N}=193$ \\
\hline Alcohol (ACL) & $123(64)$ \\
\hline Cotinine (COT) & $113(59)$ \\
\hline Tetrahydrocannabinol (THC) & $95(49)$ \\
\hline Amphetamine (AMP) & $59(31)$ \\
\hline Benzodiazepine (BZO) & $10(5.2)$ \\
\hline Opiates (OPI) & $5(2.6)$ \\
\hline
\end{tabular}


Table 3: Univariate and multivariate analysis of features associated with university students in Mombasa, Kenya testing positive for any drug in 2017

\begin{tabular}{|c|c|c|c|c|}
\hline & \multicolumn{2}{|c|}{ Univariate analysis } & \multicolumn{2}{|c|}{ Multivariate analysis } \\
\hline & Crude RR $(95 \% \mathrm{CI})$ & P-value & Adjusted RR (95\% & P-value \\
\hline \multicolumn{5}{|l|}{ Socio-demographics Characteristics } \\
\hline Age in months & $1.03(0.99,1.07)$ & 0.18 & $1.00(0.93,1.08)$ & 0.98 \\
\hline \multicolumn{5}{|l|}{ Gender } \\
\hline Male & Reference & & Reference & \\
\hline Female & $1.08(0.87,1.32)$ & 0.49 & $1.02(0.74,1.40)$ & 0.92 \\
\hline \multicolumn{5}{|l|}{ Education level } \\
\hline Degree student & Reference & & Reference & \\
\hline Diploma student & $0.94(0.69,1.27)$ & 0.68 & $1.06(0.67,1.67)$ & 0.81 \\
\hline \multicolumn{5}{|l|}{ Birth order } \\
\hline First born & Reference & & Reference & \\
\hline $2^{\text {nd }}$ born & $1.04(0.76,1.43)$ & 0.80 & $1.03(0.66,1.62)$ & 0.88 \\
\hline $3^{\text {rd }}$ born & $1.36(1.03,1.79)$ & 0.03 & $1.16(0.76,1.77)$ & 0.50 \\
\hline $4^{\text {th }}$ born and above & $1.17(0.89,1.53)$ & 0.26 & $1.05(0.71,1.54)$ & 0.82 \\
\hline \multicolumn{5}{|l|}{ Faculty enrolled } \\
\hline Business studies & Reference & & Reference & \\
\hline Applied sciences & $0.93(0.69,1.24)$ & 0.62 & $0.92(0.61,1.38)$ & 0.68 \\
\hline Engineering & $1.26(0.97,1.62)$ & 0.08 & $1.19(0.81,1.76)$ & 0.38 \\
\hline Humanities \& social sciences & $1.12(0.81,1.55)$ & 0.50 & $1.08(0.67,1.75)$ & 0.76 \\
\hline Computing \& informatics & $1.22(0.83,1.78)$ & 0.31 & $1.12(0.62,2.02)$ & 0.70 \\
\hline \multicolumn{5}{|l|}{ Year of study } \\
\hline First year & Reference & & Reference & \\
\hline Second year & $1.60(1.08,2.37)$ & 0.02 & $1.28(0.74,2.22)$ & 0.38 \\
\hline Third year & $1.76(1.22,2.54)$ & 0.003 & $1.50(0.88,2.56)$ & 0.14 \\
\hline Fourth year & $1.49(1.02,2.17)$ & 0.04 & $1.32(0.75,2.30)$ & 0.33 \\
\hline \multicolumn{5}{|l|}{ Residence or accommodation type } \\
\hline University Hostel and Its Environs & Reference & & Reference & \\
\hline Mishomoroni and Kisauni & $0.99(0.67,1.44)$ & 0.94 & $0.97(0.65,1.44)$ & 0.88 \\
\hline Within town* & $1.94(1.37,2.73)$ & $<0.001$ & $1.67(1.16,2.42)$ & 0.006 \\
\hline Bamburi and Bombolulu & $1.69(0.93,3.09)$ & 0.09 & $1.82(0.97,3.40)$ & 0.06 \\
\hline \multicolumn{5}{|l|}{ Marital status } \\
\hline Never Married & Reference & & Reference & \\
\hline Married/cohabiting & $0.82(0.48,1.41)$ & 0.47 & $0.87(0.42,1.79)$ & 0.70 \\
\hline \multicolumn{5}{|l|}{ Income/pocket money/month -USD } \\
\hline$<50$ & Reference & & Reference & \\
\hline Between 50 and 100 & $1.36(0.99,1.87)$ & 0.06 & $1.13(0.81,1.59)$ & 0.47 \\
\hline$>100$ & $0.86(0.60,1.25)$ & 0.44 & $0.84(0.57,1.25)$ & 0.40 \\
\hline \multicolumn{5}{|l|}{ Current number of sexual partners } \\
\hline None & Reference & & Reference & \\
\hline One & $1.67(1.12,2.49)$ & 0.01 & $1.43(0.95,2.17)$ & 0.09 \\
\hline Two and above & $2.58(1.62,4.13)$ & $<0.001$ & $2.06(1.26,3.37)$ & 0.004 \\
\hline
\end{tabular}

*Includes Makupa, Sparki and Majengo; RR-relative risk; AUC-Area under receiver operating characteristics; CI-confidence interval; The RR and P-values re from a log-binomial regression model. The multivariate model AUC: 0.77 (95\% CI 0.72, 0.82 ). 1 USD = Kshs. 102 
Table 4: Univariate and multivariate analysis of features associated with self reported drug use history of students in a public university in Mombasa, Kenya in 2017

\begin{tabular}{|c|c|c|c|c|}
\hline \multirow{2}{*}{ Socio demographics characteristics } & \multicolumn{2}{|c|}{ Univariate analysis } & \multicolumn{2}{|c|}{ Multivariate analysis } \\
\hline & Crude RR $(95 \%$ & $\mathrm{P}$-value & Adjusted RR (95\% & P-value \\
\hline Age in months & $1.02(0.98,1.05)$ & 0.39 & $0.98(0.91,1.05)$ & 0.57 \\
\hline \multicolumn{5}{|l|}{ Gender } \\
\hline Male & Reference & & Reference & \\
\hline Female & $1.03(0.86,1.23)$ & 0.76 & $0.96(0.71,1.30)$ & 0.81 \\
\hline \multicolumn{5}{|l|}{ Education level } \\
\hline Degree student & Reference & & Reference & \\
\hline Diploma student & $0.99(0.77,1.27)$ & 0.94 & $1.18(0.77,1.30)$ & 0.44 \\
\hline \multicolumn{5}{|l|}{ Birth order } \\
\hline First born & Reference & & Reference & \\
\hline $2^{\text {nd }}$ born & $0.98(0.75,1.29)$ & 0.89 & $0.96(0.63,1.45)$ & 0.83 \\
\hline $3^{\text {rd }}$ born & $1.25(0.99,1.58)$ & 0.07 & $1.10(0.74,1.63)$ & 0.65 \\
\hline $4^{\text {th }}$ born and above & $1.09(0.87,1.37)$ & 0.47 & $0.98(0.69,1.40)$ & 0.92 \\
\hline \multicolumn{5}{|l|}{ School enrolled } \\
\hline School of Business & Reference & & Reference & \\
\hline School of Applied \& Health sciences & $0.94(0.73,1.21)$ & 0.64 & $0.94(0.65,1.38)$ & 0.76 \\
\hline School Engineering & $1.22(0.98,1.52)$ & 0.07 & $1.16(0.80,1.67)$ & 0.43 \\
\hline School Humanities \&Social Sciences & $1.04(0.77,1.39)$ & 0.81 & $0.99(0.63,1.57)$ & 0.96 \\
\hline Institute of Computing \&Informatics & $1.19(0.86,1.64)$ & 0.31 & $1.11(0.64,1.93)$ & 0.71 \\
\hline \multicolumn{5}{|l|}{ Year of study } \\
\hline First year & Reference & & Reference & \\
\hline Second year & $1.48(1.05,2.07)$ & 0.02 & $1.26(0.76,2.09)$ & 0.37 \\
\hline Third year & $1.58(1.15,2.16)$ & 0.005 & $1.43(0.88,2.33)$ & 0.15 \\
\hline Fourth year and above & $1.45(1.06,2.00)$ & 0.02 & $1.40(0.84,2.33)$ & 0.19 \\
\hline \multicolumn{5}{|l|}{ Residence or accommodation type } \\
\hline University Hostel and its environs & Reference & & Reference & \\
\hline Mishomoroni and Kisauni & $0.97(0.69,1.37)$ & 0.88 & $0.98(0.68,1.40)$ & 0.91 \\
\hline Within town* & $1.70(1.23,2.34)$ & 0.001 & $1.48(1.05,2.08)$ & 0.03 \\
\hline Bamburi and Bombolulu & $1.39(0.77,2.50)$ & 0.28 & $1.45(0.79,2.68)$ & 0.23 \\
\hline \multicolumn{5}{|l|}{ Marital status } \\
\hline Never Married & Reference & & Reference & \\
\hline Married/cohabiting & $0.99(0.67,1.47)$ & 0.98 & $1.07(0.57,2.01)$ & 0.83 \\
\hline \multicolumn{5}{|l|}{ Income/Pocket money/month -USD } \\
\hline$<50$ & Reference & & Reference & \\
\hline Between 50 and 100 & $1.42(1.05,1.91)$ & 0.02 & $1.23(0.90,1.69)$ & 0.19 \\
\hline$>100$ & $0.88(0.62,1.25)$ & 0.47 & $0.85(0.58,1.22)$ & 0.37 \\
\hline \multicolumn{5}{|l|}{ Current number of sexual } \\
\hline None & Reference & & Reference & \\
\hline One & $1.73(1.19,2.51)$ & 0.004 & $1.55(1.05,2.28)$ & 0.03 \\
\hline Two and above & $2.44(1.57,3.81)$ & $<0.001$ & $2.05(1.28,3.27)$ & 0.003 \\
\hline
\end{tabular}

*Includes resident in Makupa, Sparki and Majengo, RR-relative risk, AUC-Area under receiver operating characteristics, CI-confidence interval, The RR and P-values re from a log-binomial regression model. The multivariate model AUC: 0.75 (95\% CI 0.71, 0.80) 
Figure 1: Combinations of self reported used drugs (A), drugs detected by saliva test (B) and poly-drug use among students attending a public university in Mombasa, Kenya in 2017

A

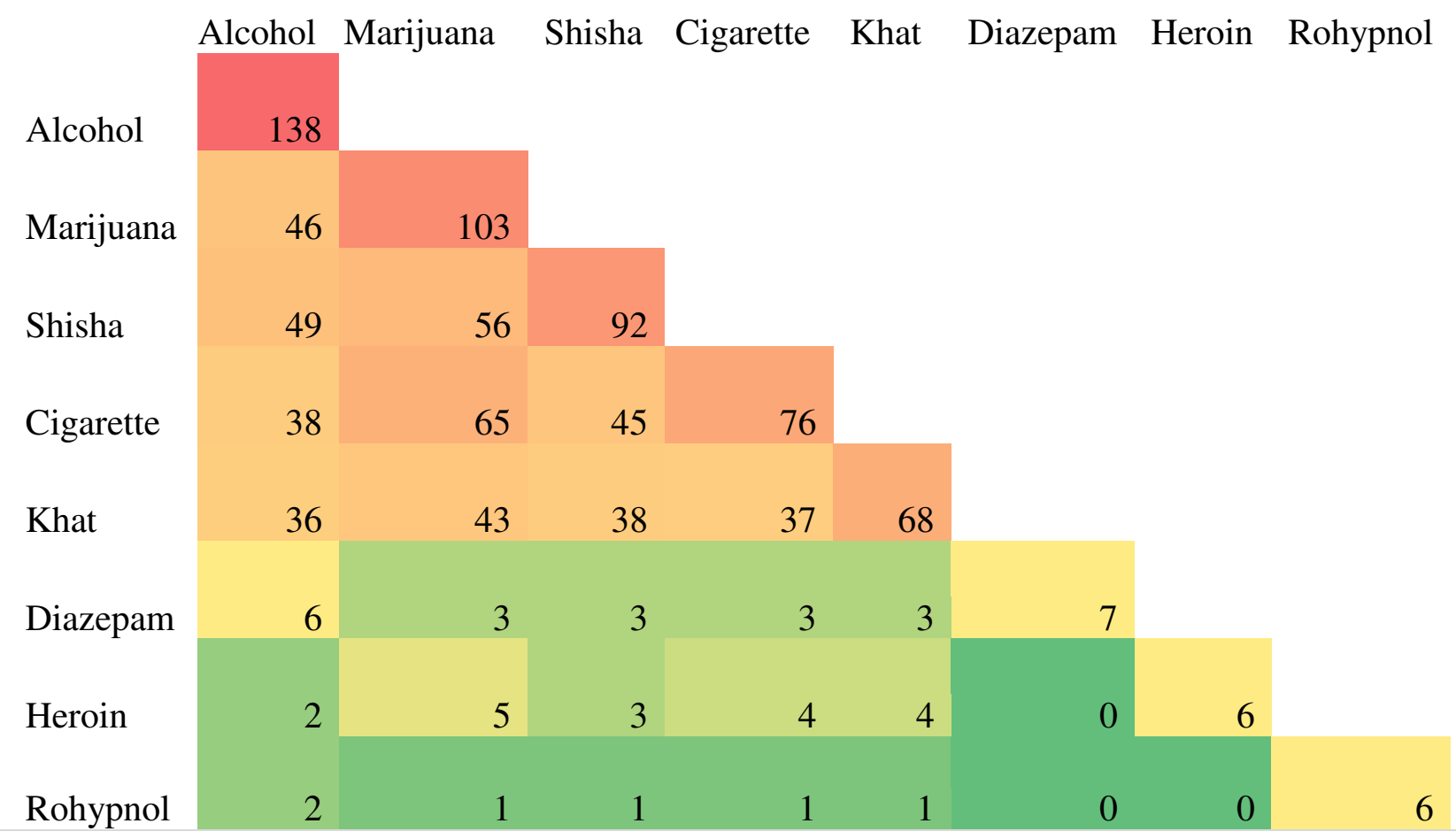

B

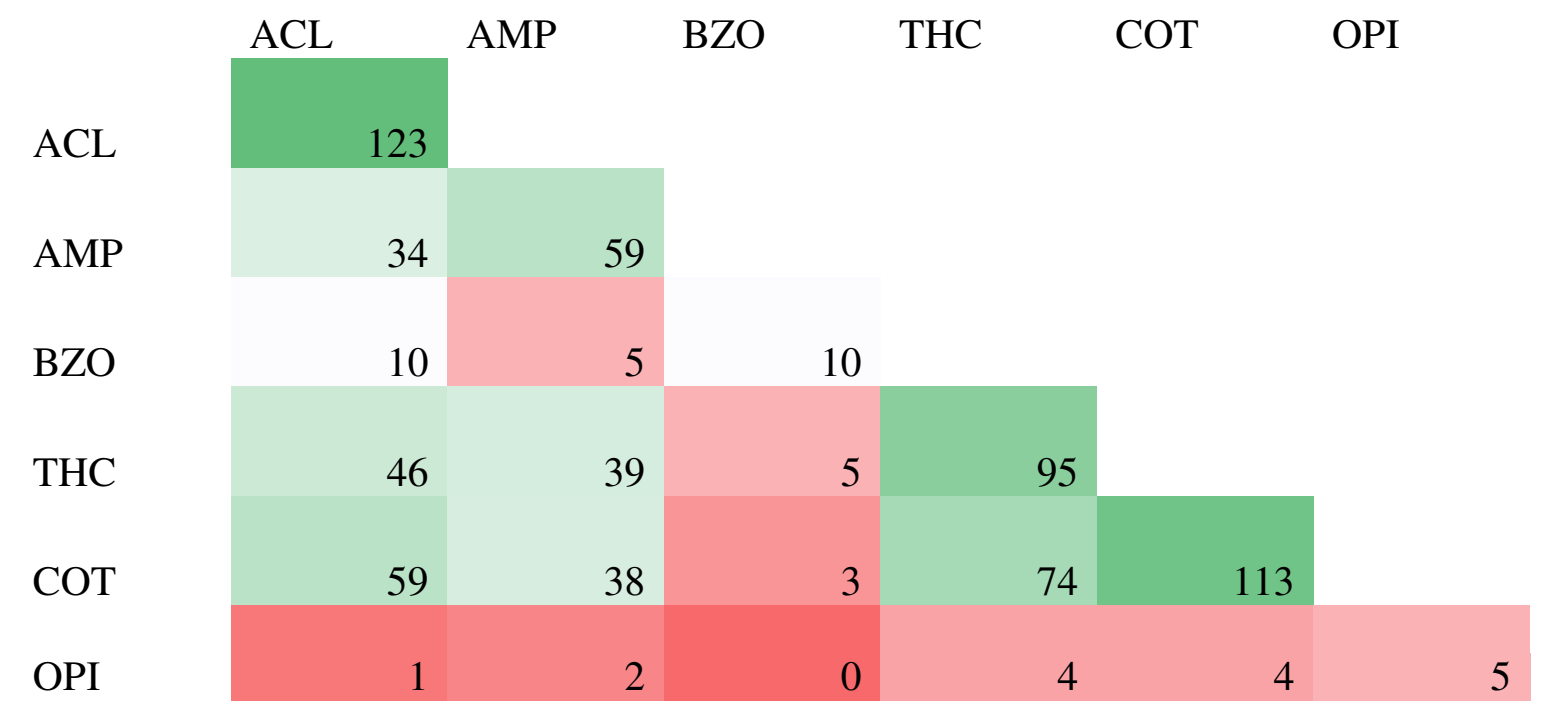

The figures are heat map showing the intensity/numbers of drug combinations, ACL-alcohol, AMP-amphetamine, BZO-benzodiazepines, THCtetrahydrocannabinol, COT-cotinine, OPI-Opiates 


\section{References}

1. UNODC, (2019). World Drug Report 2019. Accessed on $7^{\text {th }}$ Mar 2020 via https://wdr.unodc.org/wdr2019/.

2. WHO, (2017). Substance Abuse. Accessed on $7^{\text {th }}$ Mar 2020 via https://www.afro.who.int/health-topics/substance-abuse

3. Madeline BB, DiBello AM, Balestrieri SG, Miller MB, Merrill JE, Lowery AD, Mastroleo NR \& Carey KB (2017). Off-Campus Residence as a Risk Factor for Heavy Drinking Among College Students. Journal of Substance Use \& Misuse; 52 (9), 1236-41.

4. Lipari RN \& Jean-Francois BA (2016). Day in the Life of College Students Aged 18 to 22: Substance Use Facts. The CBHSQ Report: Center for Behavioral Health Statistics and Quality, Substance Abuse and Mental Health Services Administration, Rockville, MD. Accessed on $21^{\text {st }}$ May 2019 via https://www.samhsa.gov/data/sites/default/files/report_2361/ShortReport-2361.html

5. NIAAA, (2018). Time for Parents to Discuss the Risks of College Drinking. Accessed on $12^{\text {th }}$ Mar 2020 via https://www.niaaa.nih.gov/publications/brochures-and-factsheets/time-for-parents-discuss-risks-college-drinking.

6. Skidmore CR, Kaufman EA \& Crowell SE (2016). Substance use among college students. Child and Adolescent Psychiatric Clinics of North America, 25(4), 735-753.

7. Ayala EE, Roseman D, Winseman JS \& Mason HRC (2017). Prevalence, perceptions and consequences of substance use in medical students. Medical Education Online; 22(1).

8. Arria AM, Caldeira KM, Allen HK,. Bugbee BA, Vincent KB \& O'Grady KE (2017). Prevalence and incidence of drug use among college students: an 8-year longitudinal analysis. The American Journal of Drug and Alcohol Abuse, 43:6, 711-718.

9. Erevik EK, Pallesen S, Vedaa $\varnothing$, Andreassen CS, \& Torsheim T (2017). Alcohol use among Norwegian students: Demographics, personality and psychological health correlates of drinking patterns. Nordic Studies on Alcohol and Drugs; 34(5), 415-429.

10. Solbjørg MM, Gärtner KA, Knapstad M, Knudsen AK \& Skogen JS (2017). The Norwegian student introductory week: who takes part, and is participation associated with better social integration and satisfaction among students? European Journal of Higher Education; 7:2, 136-152.

11. Arora A, Kannan S, Gowri S, Choudhary S, Sudarasanan S, Khosla PP (2016). Substance abuse amongst the medical graduate students in a developing country.The Indian Journal of Medical Research;143(1):101-103 
12. Kaur R, Singh T, Basu D and Kumar R (2019).Prevalence and pattern of psychoactive substance use among female students aged 18-25 years in universities of North India. International Journal of Community Medicine and Public Health, 6 (2), PP 602.

13. Bajwa HZ, Al-Turki ASA, Dawas AMK, Behbehani MQ, Al-Mutairi AMA, AlMahmoud S, Shukkur M, Thalib L (2013). Prevalence and Factors Associated with the Use of Illicit Substances among Male University Students in Kuwait. Journal of Medical Principles and Practice; 22:458-463.

14. Osman T, Victor C, Abdulmoneim A, Mohammed H, Abdalla F, Ahmed A, Ali E \& Mohammed W (2016). Epidemiology of Substance Use among University Students in Sudan. Journal of addiction. 2016 (2016). DOI: 10.1155/2016/2476164

15. Alemu G, Alebel A, Zegeye A, Tesfaye B (2018). Prevalence and predictors of khat chewing among Ethiopian university students: A systematic review and meta-analysis. PLoS ONE 13(4):e0195718.

16. Atwoli L, Mungla PA, Ndung'u MN, Kinoti KC, Ogot EM (2011). Prevalence of substance use among college students in Eldoret, western Kenya. BMC Psychiatry ;11(34).

17. McNutt LA, Wu C, Xue X, Hafner JP (2003). Estimating the Relative Risk in Cohort Studies and Clinical Trials of Common Outcomes. American Journal of Epidemiology; 157 (10), pp 940-943.

18. Fisher AA, Laing JE, Stoeckel JE and Townsend JW (1998). Handbook for Family Planning Operations Research Design. Population Council, New York, USA.2nd ed., P43. Accessed on $20^{\text {th }}$ Mar. 2020 via www.popcouncil.org.

19. Quek, LH, Chan GC, White A, Connor JP, Baker PJ, Saunders JB \& Kelly AB (2013). Concurrent and simultaneous polydrug use: latent class analysis of an Australian nationally representative sample of young adults. Frontiers in public health; 1(61).

20. De Veld L, Inge MW, Van Hoof JJ \& Van der Lely (2018). The relationship between birth order and acute alcohol intoxication among Dutch adolescents. Journal of Child \& Adolescent Substance Abuse; 27:5(6), pp-334-340.

21. Barclay K, Myrskyla M, Tynelius P, Berglind D \& Rasmussen F. (2016). Birth order and hospitalization for alcohol and narcotics use in Sweden. Drug and Alcohol Dependence; 167(2016), pp. 15-22. 
22. Valkov P (2018).Birth order and its relatedness to substance use disorder: an empirical resea in Bulgaria. International journal of emotional education; 10 (2), pp 154 - 158.

23. Tesfaye G, Derese A, \& Hambisa MT (2014). Substance Use and Associated Factors among University Students in Ethiopia: A Cross-Sectional Study. Journal of addiction; 2014 (2014).

24. Pascoe CM, Sarah EH \& Alexandra GP (2020). The impact of stress on students in secondary school and higher education. International Journal of Adolescence and Youth; 25(1), pp 104-112.

25. Estevez AG, Roche JRF, Saborit AR, Espinosa AHR \& Rodriguez DL (2019). Relationship between social skills and alcohol. International journal of health sciences; 3(1), pp 1-8.

26. Tavolacci MP, Ladner J, Grigioni S, Richard L, Villet H \& Dechelotte P (2013). Prevalence and association of perceived stress, substance use and behavioral addictions: a cross-sectional study among university students in France, 2009-2011. BMC public health; 13(724).

27. Khaddouma A, Shorey RC, Brasfield H, Febres J, Zapor H, Elmquist J \& Stuart G. L. (2016). Drinking and Dating: Examining the Link between Relationship Satisfaction, Hazardous Drinking, and Readiness-to-Change in College Dating Relationships. Journal of college student development; 57(1), pp 32-46.

28. Rusby JC, Light JM, Crowley R \& Westling E (2018). Influence of parent-youth relationship, parental monitoring, and parent substance use on adolescent substance use onset. Journal of family psychology; 32(3), pp 310-320.

29. Benz MB, DiBello AM, Balestrieri SG, Miller MB, Merrill JE, Lowery AD, Mastroleo NR \& Carey KB (2017). Off-Campus Residence as a Risk Factor for Heavy Drinking Among College Students. Substance Use and Misuse;52(9):1236-41.

30. Musyoka CM, Mbwayo A and Mathai M(2019). Prevalence and patterns of substance use among first year students in a Public University in Kenya. Journal of Psychology and Cognition;4(2):31-36.

31. Chris CM (2019). High Socioeconomic Status Predicts Substance Use and Alcohol Consumption in US Undergraduates. Journal of Substance Use and Misuse; 54(6). 
32. Gebremariam TB, Mruts KB \& Neway TK (2018). Substance use and associated factors among Debre Berhan University students, Central Ethiopia. Journal of Substance Abuse Treatment; 13(13).

33. Huang LL, Sutfin EL, Kowitt S, Patel T, Ranney L\& Goldstein AO (2017). Trends and Correlates of Hookah Use Among High School Students in North Carolina. North Carolina medical journal; 78(3), 149-155.

34. Choudhry V, Agardh A, Stafström M et al (2014). Patterns of alcohol consumption and risky sexual behavior: a cross-sectional study among Ugandan university students. $B M C$ Public Health; 14(128).

35. Yi S, Te V, Pengpid S \& Peltzer K (2018). Social and behavioural factors associated with risky sexual behaviours among university students in nine ASEAN countries: a multicountry cross-sectional study. Journal of Social Aspects of HIV/AIDS Research Alliance; 15(1), 71-79.

36. Brown JL, Gause NK, \& Northern N (2016). The Association between Alcohol and Sexual Risk Behaviors among College Students: A Review. Current addiction reports; 3(4), pp 349-355.

37. Ware E, Tura G, Alemu T et al. (2018). Disparities in risky sexual behavior among khat chewer and non- chewer college students in Southern Ethiopia: a comparative crosssectional study. BMC Public Health; 18 (558).

38. DiBello AM, Benz BM, Miller MB, Merrill JE \& Carey KB (2018). Examining residence status as a risk factor for health risk behaviors among college students. Journal of American College Health; 66 (3), pp 187-193.

39. National Center for Biotechnology Information (2020a). PubChem Database. Cotinine, $\mathrm{CID}=854019$. Accessed on $22^{\text {th }}$ Mar 2020 via https://pubchem.ncbi.nlm.nih.gov/compound/Cotinine

40. National Center for Biotechnology Information(2020b). PubChem Database. Dronabinol, $\mathrm{CID}=16078$. Accessed on $22^{\text {th }}$ Mar 2020 via https://pubchem.ncbi.nlm.nih.gov/compound/Dronabinol

41. NACADA, 2012. Rapid Situation Assessment of the Status of Drug and Substance Abuse in Kenya. Accessed on $22^{\text {nd }}$ Mar. 2020 via https://nacada.go.ke/node/157.

42. Davoren MP, Demant, J, Shiely F \& Perry IJ (2016). Alcohol consumption among university students in Ireland and the United Kingdom from 2002 to 2014: a systematic review. BMC public health, 16 (173). 
43. Vakilian K, Keramat A, Abass SM, Chaman R (2019). Experience Assessment of Tobacco Smoking, Alcohol Drinking, and Substance Use among Shahroud University Students by Crosswise Model Estimation -The Alarm to Families. The open public health journal. 12, Pp 33-37.

44. Kandel D and Faust R (1975). Sequence and Stages in Patterns of Adolescent Drug Use. Archives Of General Psychiatry; 32(7):923-932.

45. Miller ML \& Hurd YL (2017). Testing the Gateway Hypothesis. Neuropsychopharmacology; 42(5), 985-986.

46. Lorant V, Nicaise P, Soto VE \& d'Hoore W (2013). Alcohol drinking among college students: college responsibility for personal troubles. BMC public health, 13 (615).

47. GoK, (2010). Alcoholic Drinks Control Act. Accessed on 22 ${ }^{\text {nd }}$ Mar. 2020 via http://kenyalaw.org/kl/fileadmin/pdfdownloads/Acts/Alcoholic_Drinks_Control_Act_N o4of2010.pdf.

48. Omotehinwa OJ, Japheths O, Damascene IJ \& Habtu, M (2018). Shisha use among students in a private university in Kigali city, Rwanda: prevalence and associated factors. BMC Public Health; 18(1), pp-713.

49. Rizvi F, Naz L and Nazneen Z (2019). Perception of shisha smoking \& drug abuse Among university students of Karachi. Pakistan Journal of Neurological Sciences (PJNS); 14 (2).

50. Gok, (2017). Public Health Act, Chapter 242. Accessed on 22 ${ }^{\text {nd }}$ Mar. 2020 via http://www.kenyalaw.org/k1/fileadmin/pdfdownloads/Acts/PublicHealthActCap242.pdf.

51. CDC, (2020). Hookahs. Accessed on 22 $2^{\text {nd }}$ Mar. 2020 via https://www.cdc.gov/tobacco/data_statistics/fact_sheets/tobacco_industry/hookahs/index. htm.

52. GoK, (2007). The Tobacco Control Act. Accessed on 22 $2^{\text {nd }}$ Mar. 2020 viahttp://kenyalaw.org/tobacco-control-act-2007/pdf.

53. Jain R, Chang CC, Koto MA et al (2018). Cannabis use and knowledge among medical students at the University of the Free State, Bloemfontein, South Africa. Journal of Child and Adolescent Mental Health. (1):19-26. 
54. GoK, (1994). Narcotic Drugs and Psychotropic Substances (Control) Act. Accessed on $22^{\text {nd }} \quad$ Mar. 2020. http://kenyalaw.org/kl/fileadmin/pdfdownloads/Acts/NarcoticDrugsandPsychotropicSubs tances_Control_Act_Cap245.pdf.

55. Smith JL, De Blasio FM, Iredale JM, Matthews AJ, Bruno R, Dwyer M, Batt T et al.' (2017). Verbal Learning and Memory in Cannabis and Alcohol Users: An Event-Related Potential Investigation. Frontiers in psychology, 8, 2129.

56. Roba H, Beyene A, Irenso A et al., (2019). Prevalence of lifetime substances use among students in Ethiopia: a systematic review and meta-analysis. Systematic Review; 8(326).

57. Ayano G, Yohannis K \& Abraha M (2019). Epidemiology of khat (Catha edulis) consumption among university students: a meta-analysis. BMC Public Health; 19 (150).

58. Hernández-Serrano O, Gras ME, Font-Mayolas S (2018). Concurrent and Simultaneous Use of Cannabis and Tobacco and Its Relationship with Academic Achievement amongst University Students. Journal of Behavioral Science; 8(3): 31.

59. Oliveira LG, Alberghini DG, Santos BD \& Andrade AG (2013). Polydrug use among college students in Brazil: a nationwide survey. Revista Brasileira de Psiquiatria; 35 (3) pp.221-230.

60. Deressa W and Azazh A (2011). Substance use and its predictors among undergraduate medical students of Addis Ababa University in Ethiopia. BMC Public Health 11, 660.

61. Downey LA, King R, Papafotiou K, Swann P, Ogden E, Boorman M, Stough C (2013). The effects of cannabis and alcohol on simulated driving: Influences of dose and experience. Accident Analysis and Prevention; 50, pp 879-86.

62. Mennis J, Stahler GJ \& Mason MJ (2016). Risky Substance Use Environments and Addiction: A New Frontier for Environmental Justice Research. International journal of environmental research and public health; 13(6), pp 607. 


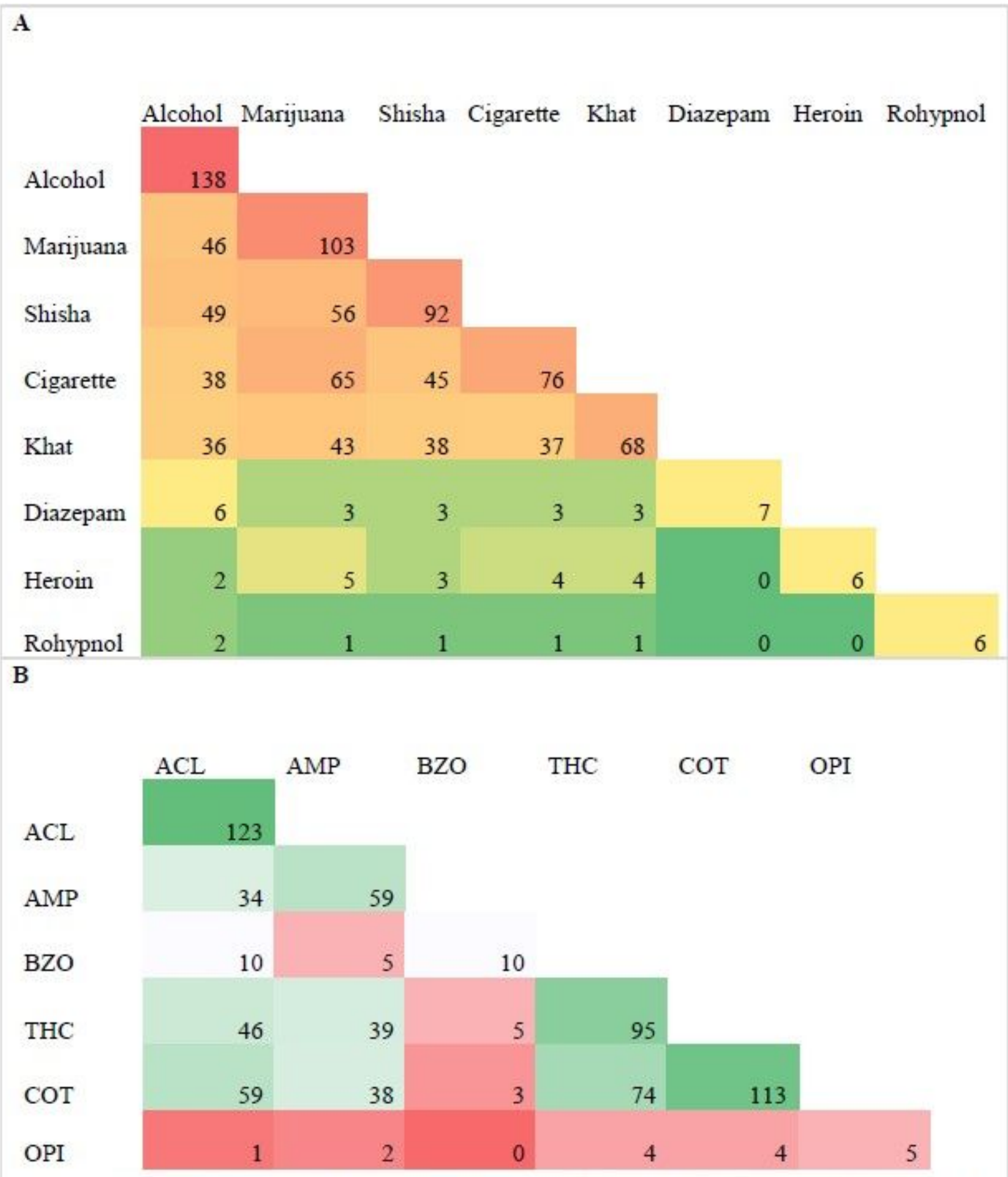

The figures are heat map showing the intensity/numbers of drug combinations, ACL-alcohol, AMP-amphetamine, BZO-benzodiazepines, THCtetrahydrocannabinol, COT-cotinine, OPI-Opiates

\section{Figure 1}

Combinations of self reported used drugs (A), drugs detected by saliva test (B) and poly-drug use among students attending a public university in Mombasa, Kenya in 2017 